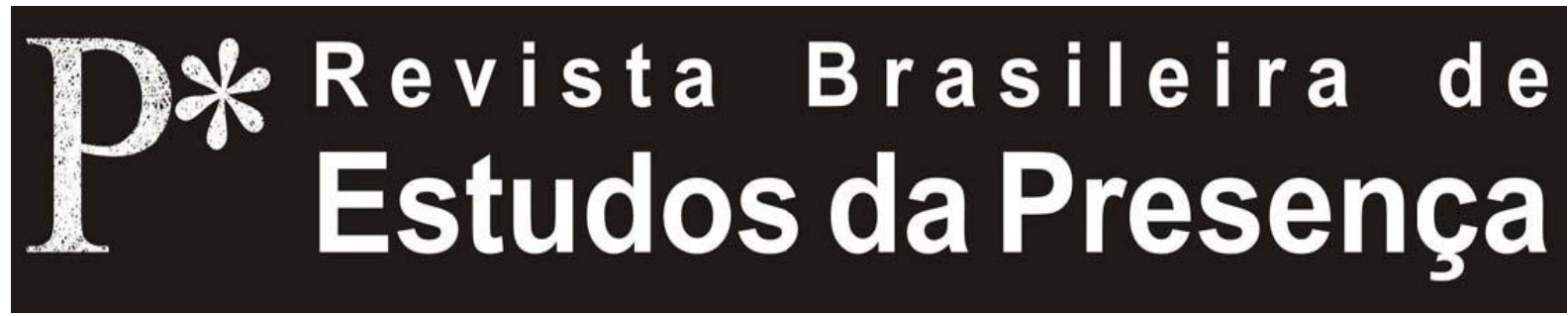

DOI - http://dx.doi.org/10.1590/2237-266030315

ISSN 2237-2660

\title{
François Delsarte e a Dança Moderna: um encontro na expressividade corporal
}

Elisa Teixeira de Souza

Universidade de Brasília - UnB, Brasília, DF, Brasil

RESUMO - François Delsarte e a Dança Moderna: um encontro na expressividade corporal - Este estudo aborda o sistema de François Delsarte para a expressividade corporal, chamado Estética Aplicada. Apresenta dados relacionados à trajetória de François Delsarte, como origem, formação e fundamentação teórica. Discute as leis da expressividade gestual formuladas por Delsarte - a Lei da Trindade, a Lei da Correspondência e as Nove Leis do Movimento - bem como sua difusão e utilização na dança moderna, incluindo nessa discussão nomes de precursores da dança moderna como Isadora Duncan, Ruth Saint Denis, Ted Shawn, Vaslav Nijinsky, Rudolf Laban e Mary Wigman.

Palavras-chave: François Delsarte. Estética Aplicada. Delsartismo. Dança Moderna. História da Dança.

ABSTRACT - François Delsarte and Modern Dance: an encounter in physical expression - This study addresses François Delsarte's system of expression, known as Applied Aesthetics. It presents data related to François Delsarte's career, such as personal and professional life and his theoretical background. It discusses the laws of gestural expression formulated by Delsarte - Trinity Law, the Law of Correspondence and the Nine Laws of Motion - as well as their dissemination and utilization in modern dance; this discussion mentions some pioneers of modern dance, such as Isadora Duncan, Ruth Saint Denis, Ted Shawn, Vaslav Nijinsky, Rudolf Laban and Mary Wigman.

Keywords: François Delsarte. Applied Aesthetics. Delsartism. Modern dance. History of dance.

RÉSUMÉ - François Delsarte et la Danse Moderne: une rencontre dans l'expressivité corporelle - Cette étude aborde le système de François Delsarte pour l'expressivité corporelle, appelée Esthétique Appliquée. Il présente des données relatives à la trajectoire de François Delsarte, comme ses origines, sa formation et ses références théoriques. Il analyse les lois de l'expression gestuelle formulées par Delsarte - la Loi de la Trinité, la Loi de la Correspondance et les Neuf Lois du Mouvement - et leur diffusion et utilisation dans la danse moderne. Dans cette réflexion sont évoqués les noms des précurseurs de la danse moderne comme Isadora Duncan, Ruth Saint-Denis, Ted Shawn, Vaslav Nijinsky, Rudolf Laban et Mary Wigman. Mots-clés: François Delsarte. Esthétique Appliquée. Delsartisme. Danse Moderne. Histoire de la Danse. 
Nos territórios da expressividade cênica corporal, o nome de François Delsarte (1811-1871) ocupa um significativo espaço. Nos entremeios do século XIX para o século XX, seu sistema de análise da expressividade gestual corporal e a exploração prática de seus princípios foi base para inúmeros artistas e, dentre esses, para aqueles que buscaram inovações expressivas para o corpo em cena na linguagem da dança. $\mathrm{O}$ pensamento e os treinamentos elaborados por Delsarte se voltavam para o teatro, o canto, a declamação e as artes plásticas (Dasgupta, 1993). E foi utilizado no cinema mudo e na dança, ainda que tal utilização não tenha sido vislumbrada por ele. A influência que exerceu foi forte na França e nos Estados Unidos da América (EUA); considerável em países vizinhos e próximos da França, como Alemanha, Suíça e Itália; e presente em território Russo (Taylor; Whyman, 2005).

Nas décadas iniciais do século XX, nos EUA, e pouco depois na Europa, derivações práticas do sistema de Delsarte geraram uma moda performática inspirada em gestuais estatuários de motivos míticos helênicos, e estas realizações pantomímicas, com o tempo, acabaram por desembocar em formas abstratas de movimento; em novas maneiras de se exercer a expressividade corporal. Tal abstração da pantomima delsarteana integrou em forte medida as investigações expressivas desenvolvidas por Isadora Duncan (Ruyter, 1996), Ruth Saint Denis e Ted Shawn (Thomas, 1995), os precursores da dança moderna; provocou e nutriu o pensamento de Émile Jaques-Dalcroze e de Rudolf Laban (Hecht, 1971); apontou novos caminhos para Vaslav Nijinsky no balé moderno (Garaudy, 1980).

Neste artigo, pretende-se apresentar sinteticamente o sistema expressivo gestual de Delsarte, com enfoque para as leis elaboradas por ele, bem como alguns de seus desdobramentos, e discutir relações existentes entre o pensamento delsarteano e a dança moderna. A fim de se possibilitar um entendimento mais contextualizado, serão abordadas no primeiro tópico do texto algumas informações preliminares, como pontos da trajetória de Delsarte e aspectos de seu pensamento. 


\section{Quem foi François Delsarte?}

François Delsarte foi cantor, recitador, compositor, professor de canto, de oratória e de pantomima (Porte, 1992). Foi um grande investigador da expressividade gestual ${ }^{1}$ humana, tendo sido um importante pioneiro na análise expressiva do gesto corporal. Durante as décadas intermediárias dos anos 1800, divulgou intensamente seu sistema de análise da expressividade gestual na sociedade intelectual e artística parisiense, bem como possíveis aplicações desse sistema nas práticas artísticas (Ruyter, 1996). Dentre os famosos e influentes da elite da sociedade cultural de Paris, foram seus alunos: Eugène Delacroix, Gioachino Rossini, Georges Bizet e Théophile Gautier (Madureira, 2002). De acordo com Ted Shawn (1963), Delsarte, enquanto homem católico profundamente religioso, defendeu a fé em meio às manifestações anticlericais ocorridas na França no século XIX. Foi editor e publicador de materiais relacionados à música, além de ter sido inventor, talento que, segundo Shawn, herdou do pai. Dentre suas invenções estavam um aparelho que afinava pianos, um equipamento para direcionar a navegação e um cardiógrafo. Sua carreira como cantor foi prematuramente interrompida por um problema de saúde vocal, fazendo com que ele se voltasse para o trabalho no meio teatral.

A situação negativa em que Delsarte se encontrou o motivou a investigar a relação entre voz, gesto e emoção na cena, movido pelo pensamento de que a linguagem gestual corporal, em sua capacidade de expressar o âmago do homem, seria suprema dentre todas as linguagens artísticas. Desejoso de combater o direcionamento que o Conservatório de Paris tomava no ensino de jovens artistas, o qual considerava idiossincrático e prejudicial, passou a encarar como missão de vida a tarefa de desvelar as grandes leis universais da expressividade dos corpos, bem como os princípios gerais de aplicação dessas leis na expressividade das obras em diversas linguagens artísticas (Shawn, 1963). Estudou durante décadas o comportamento gestual corporal e vocal dos indivíduos, e também a expressividade gestual dos personagens de quadros e esculturas de motivos helênicos, relacionando posturas 
expressivas com significados, baseado em valores morais do pensamento católico. Como coloca José Rafael Madureira (2002), Delsarte acabou por tornar-se um teórico autodidata do gesto e da voz, passando a oferecer cursos de expressividade gestual corporal e vocal. Realizava cursos teóricos, que funcionavam como grupos de palestras, onde apresentava os pressupostos, as leis e os princípios de sua teoria. Segundo Shawn (1963), tudo indica que em suas palestras ocorriam demonstrações feitas por ele próprio, cantando, declamando e realizando pantomimas, ou por algum de seus discípulos. Os frequentadores eram cantores, compositores, atores, pintores, escultores, filósofos e oradores, como políticos e religiosos. Também deu aulas particulares para importantes artistas do canto e do drama. Shawn ressalta que o momento mais ativo de sua carreira se deu entre os anos 1839 e 1859. Faleceu no dia 20 de julho de 1871 (Porte, 1992; Shawn, 1963).

\section{Aspectos do Pensamento de Delsarte}

O corpo humano foi abordado por Delsarte, no contexto da estética elaborada por ele, enquanto objeto primordial de estudo, em um pensamento que possuiu um viés profundamente religioso. Considerava o homem instrumento e obra-prima de Deus. Defendeu tal perspectiva para o estudo da Estética em palestras dadas em universidades, como as que proferiu na Société Philotechnique de Paris (Porte, 1992, p. 274), na Ecole de Médecine da Universidade Paris VIII (Porte, 1992, p. 233), e no evento Soirées Littéraires de l'Athénée (Porte, 1992 , p. 215). Buscava reportar para o treinamento do ator e do cantor o conhecimento daquilo que acreditava ser o conjunto dos mecanismos da regência divina sobre a expressividade do homem. Fortes ideais morais moviam o objetivo maior da arte defendida por Delsarte: a busca da verdade, da beleza e da bondade deveriam guiar o artista em seu trabalho, para que ele pudesse refletir a perfeição divina.

Em seu direcionamento científico foi positivista, sendo sua análise expressiva do gesto semanticamente determinista e formalmente hermética. Quando se discute o viés positivista da teoria delsarteana, se faz importante contextualizar a ação 
intelectual de Delsarte como produto de um momento histórico onde o positivismo estava em alta, propondo em vários campos do saber a racionalização minuciosa de unidades temporais, materiais e espaciais. Assim como Darwin, que fora seu contemporâneo, Delsarte lançou mão de observações a campo como metodologia de investigação. Como expõe Edward F. Menerth Jr., se Darwin o fez a fim de descobrir "[...] a que ponto gestos particulares são expressões de determinados estados mentais" (Darwin, 1955, p. 13 apud Menerth Jr., 1968, p. 50, tradução nossa) ${ }^{2}$, Delsarte o fez para descobrir "[...] como o corpo humano se move frente ao estímulo da emoção" (Shawn, 1954, p. 10 apud Menerth Jr., 1968, p. 50, tradução nossa) ${ }^{3}$. Segundo Shawn (1963), em suas saídas a campo Delsarte observou o comportamento expressivo gestual do homem em hospitais, em asilos, em situações de tumultos sociais, em caminhadas na rua, em salões burgueses, em festas populares e em brincadeiras infantis, tendo chegado a viajar longas distâncias para observar tragédias coletivas. Também estudou anatomia, frequentando aulas dessa disciplina na Sorbonne, e participando de dessecações de cadáveres.

O fundamento de suas construções teóricas vinha da filosofia clássica, da filosofia escolástica, da mística cristã, da física mecânica, da estética e da semiótica. Em relação à filosofia clássica, percebe-se uma ligação muito significativa com o pensamento de Platão, quando Delsarte expõe sua crença de que a alma encontra-se enterrada sob as ruínas do corpo, sendo que, para ele, a reconciliação entre corpo e alma seria a maior potência do artista na cena e na vida. A arte é vista como afago que o corpo proporciona à alma, a qual se encontra saudosa de sua condição puramente espiritual. Corpo e alma poderiam atingir uma sinergia transcendental quando envolvidos em/por uma genuína expressão artística. No que tange à participação de concepções da filosofia escolástica nas ideias de Delsarte, identifica-se o pensamento de Tomás de Aquino como uma forte influência. A máxima tomista de que "A natureza da alma é ser a forma do corpo" (Porte, 1992, p. 104 apud Madureira, 2002, p. 17) é presente em Delsarte. Juntos, o platonismo e o tomismo instrumentalizaram parte das construções teóricas de Delsarte. 
Para Delsarte, para que $a$ arte maior pudesse ser realizada, tudo deveria ser feito sob a tutela de uma nova ciência, tão rigorosa como qualquer outra - a ciência que acreditava ter criado - a Estética Aplicada ${ }^{4}$. Seu objeto de estudo seria a expressividade do gesto, da voz e da enunciação da palavra; sua função seria o desvendar da lógica divina que rege a expressão do homem e, seu objetivo, tornar o artista cênico capaz de expressar suas emoções na cena da maneira mais verdadeira possível. O elemento que não poderia faltar para que isso acontecesse seria o gesto, pois Delsarte o concebia como primeiro agente da alma, já que os sentimentos ou pensamentos causados por alguma expressão do mundo exterior ou por alguma imagem mental o afetam instantaneamente, pois atingem diretamente a sensitividade corporal (Stebbins, 1894). Tal impacto sensitivo da informação vinda do exterior ou de imagens mentais seria o gesto primordial, ou gesto interior. Sendo assim, o gesto visível não seria o primeiro reagente da alma, mas, sim, aquele que o causa e que o direciona: o gesto primordial. Por conceber o gesto nessa dimensão sensitiva, como impulsos pré-conscientes, Delsarte pôde elucubrar que: "[...] o mais poderoso dos gestos seria aquele que afeta o espectador sem que ele saiba" (Delsarte, 18945 s/p apud Shawn, 1963 , p. 25, tradução nossa $)^{6}$.

\section{As Leis da Estética Aplicada}

A estrutura da Estética Aplicada enquanto sistema teórico era composta por três pilares: a voz (gesto vocal, referente ao canto); a palavra (gesto falado, referente à enunciação) e o gesto (gesto corporal, referente à pantomima) ${ }^{7}$. Três disciplinas norteavam os pressupostos do sistema: a Estética, a Semiótica e a Física Mecânica, tratando-se da Estática e da Dinâmica (Shawn, 1963). A estética, para Delsarte, era "[...] a ciência das manifestações sensitivas e passionais que são o objeto da arte, e que por ela psiquicamente constituem-se em formas" (Arnaud, 1893, s/p apud Stebbins, 1894, p. 57, tradução nossa) ${ }^{8}$. A semiótica, "[...] a ciência dos signos orgânicos, pela qual a estética deve estudar as aptidões inerentes às obras de arte" (Arnaud, 1893, s/p apud Stebbins, 1894, p. 57, tradução nossa) ${ }^{9}$. 
A física mecânica era encarada por ele como a ciência que investiga o deslocamento dos corpos no tempo e no espaço. No entanto, o referencial teórico utilizado por Delsarte, para relacionar e estruturar os conceitos que criou a partir das três disciplinas citadas, não foi um pensamento científico, mas sim o pensamento religioso católico, incluindo a filosofia escolástica e a mística cristã.

\section{A Lei da Trindade}

A concepção católica de uma existência divina tríplice, na qual Deus existe como Pai, Filho e Espírito Santo foi utilizada por Delsarte como base para a segunda grande lei da Estética Aplicada, a Lei da Trindade (Dasgupta, 1993). Essa lei postula que tudo no universo tem uma natureza tríplice que se espelha na tríplice constituição divina, de modo que todas as trindades existentes estariam envoltas em uma estrutura hierárquica. Nessa estrutura, os anjos seriam os protótipos dos homens, estando acima deles e abaixo de Deus, sendo assim o elo entre Deus e os homens. Os anjos seriam formados por três elementos: bondade, beleza e verdade; os homens também: alma, vida e espírito. Então, a trindade divina Pai-Filho-Espírito Santo daria origem à trindade angelical Beleza-Bondade-Verdade, e esta daria origem à trindade humana Vida-Alma-Espírito.

Cada componente de cada tríade existente se desdobraria em outros três elementos, multiplicando-se. Nessa perspectiva das multiplicações, a expressividade do homem seria sempre resultado de combinações dos elementos básicos que o constituem. Na cena, se o artista soubesse canalizar suas emoções e sentimentos em formas ou expressões que estivessem dentro dessa matemática divina da expressividade, ele também seria um elo entre Deus e os homens. Valendo ressaltar que, apesar do treinamento delsarteano investir na automatização das formas, visando a correta tradução a tempo das emoções em expressões, de acordo com a semântica gestual derivada da lei da trindade, o desejado ponto de chegada desse treino consistia em tornar o ator ou o cantor capaz de exprimir os sentimentos de sua alma espontaneamente e completamente (Dasgupta, 1993). 
$\mathrm{Na}$ trindade humana vida-alma-espírito, o termo vida se refere ao organismo, aos estados corpóreos. A vida se manifestaria no homem por sensações e percepções, e se expressaria por sons. O termo alma é usado conforme as concepções religiosas o entendem, ou seja, como a porção imortal do ser. Em Delsarte, a alma se manifestaria no homem por emoções e sentimentos, os quais seriam expressos consciente ou inconscientemente pelo gesto. O termo espírito significa mente, intelecto. $\mathrm{O}$ espírito se manifestaria no homem por pensamentos, e se expressaria para o mundo pela palavra, na linguagem verbal (Stebbins, 1894). Sendo assim, para cada um dos três elementos constituintes do homem existiria um aparato físico: a voz para a vida; a palavra para o espírito; o gesto para a alma.

Como se pode observar no quadro apresentado abaixo, a linguagem cromática também foi aplicada por Delsarte às trindades, sendo que as três cores elementares - o amarelo, o vermelho e o azul - eram utilizadas para representar os três elementos constituintes das trindades. No caso da trindade humana, tem-se: amarelo para a alma; vermelho para a vida; e azul para o espírito.

\begin{tabular}{|c|c|c|}
\hline 1 & $\mathbf{2}$ & $\mathbf{3}$ \\
\hline VIDA & ALMA & ESPÍRITO \\
\hline voz & gesto & palavra \\
\hline
\end{tabular}

Figura 1 - Quadro da Trindade Humana. Fonte: Autoria própria.

Em relação aos movimentos do corpo no espaço, Delsarte observou que todo movimento pode ser ou excêntrico, partindo do centro do corpo e se direcionando para as periferias do corpo, em uma expansão, ou concêntrico, partindo das periferias e se direcionando para o centro, em um recolhimento ou contração. Logo, o que está em movimento pode estar se expandindo ou se recolhendo, e o que não está em movimento está centrado ou suspenso. Desse modo, Delsarte identificou três critérios de expressividade do movimento e elaborou a trindade Excêntrico-Normal-Concêntrico, tendo se fundamentado para isso na física mecânica (Ruyter, 1996). A tríade 
excêntrico-normal-concêntrico se manifesta em movimentos de pequenas e grandes partes do corpo, assim como no movimento do corpo como um todo. Haveria a correspondência: mental ou espiritual para concêntrico; moral, emocional ou anímico para normal; e vital ou sensorial para excêntrico (Stebbins, 1894). Madureira transcreve um exemplo utilizado por Delsarte para ilustrar a manifestação dessa trindade:

\begin{abstract}
As mãos [...] relaxadas, em estado de normalidade, representam a qualidade gestual NORMAL. Mãos abertas, estendidas, indicam uma gestualidade EXCÊNTRICA. Por fim, se as mãos estiverem fechadas, contraídas, serão enquadradas como uma gestualidade CONCÊNTRICA (Madureira, 2002, p. 61-62).
\end{abstract}

Outra importante trindade elaborada por Delsarte é a trindade Tensão/Relaxamento-Forma-Equilíbrio, que se refere à plasticidade do movimento dos corpos. $\mathrm{O}$ elemento tensão-relaxamento se refere primordialmente aos movimentos ocorridos nos espaços internos do próprio corpo, e não aos movimentos do corpo na perspectiva da ocupação da espacialidade exterior. Entretanto, isso não significa que a relação entre contração e relaxamento corporal não possa causar deslocamentos espaciais. Madureira (2002) observa que a relação entre tensão e relaxamento ocorre em todo tipo de corpo: pequeno ou grande, humano, animal, ou da natureza. Quando a energia de vida flui para dentro, ocorre uma contração e, quando flui para fora, ocorre um relaxamento. Esses dois sentidos do fluxo de energia vital se revezam em um movimento constante. De acordo com Shawn (1963), Delsarte considerava essa relação de revezamento ininterrupto entre tensão e relaxamento como sendo a lei da vida; o ritmo vital. Sendo que tal relação deveria ocorrer por equivalências estabelecidas entre os dois fatores; equivalências de energia, de tempo e de espaço.

O elemento forma diz respeito à plasticidade gestual, e é sempre o resultado de uma vida, de um período da vida, ou do tempo. Para se entender uma forma humana é necessário entender a vida que a modulou, os hábitos que a marcaram, as emoções vivenciadas. De acordo com Shawn, Delsarte categorizou a forma gestual em três tipos: 
[...] a forma assumida pelo ser humano no momento de seu nascimento, ou forma constitucional; a forma relacionada às influências do ambiente e dos costumes, trazidas por experiências crescentes e causadoras de modificações, que é a forma habitual; e a forma assumida sob a influência de emoções temporárias, que é a forma efêmera (Shawn, 1963, p. 55, tradução nossa) ${ }^{10}$.

Stebbins (1894) se refere à forma efêmera como forma passional, e à forma constitucional como forma congênita. Para ela, a forma habitual seria a segunda natureza gestual do homem e estaria ligada aos sentimentos e a sua aderência na forma. Existiria também um continuum entre os três tipos de forma: "[...] tipos passionais explicam tipos habituais, e tipos habituais explicam tipos congênitos" (Stebbins, 1894, p. 65, tradução nossa) ${ }^{11}$.

O equilíbrio diz respeito à harmonia estética na plasticidade do movimento. Está ligado a um julgamento do belo, tendo-se a moral católica como parâmetro definidor do nível de beleza, ou harmonia, o que está relacionado com a significação dos gestos. No equilíbrio, a valoração da forma se dá pela maneira como se utiliza a descarga de peso em sua estruturação. Nesse ponto, entra no jogo estético delsarteano a noção de peso harmônico. Esse conceito se refere à maneira como a descarga e a transferência de peso na base ou nos pontos de apoio do corpo no chão interferem na harmonia estética da forma. O peso harmônico conferiria graça, força, beleza, vigor, eficiência e precisão aos movimentos (Stebbins, 1894).

Também voltada para a plasticidade e significação dos movimentos do corpo está a trindade Oposição-SucessãoParalelismo, que corresponde às três grandes ordens do movimento. Ela diz respeito às relações espaciais que podem ser exploradas entre os movimentos de diferentes partes do corpo. As posturas ou movimentos de oposição, paralelismo ou sucessão podem envolver tanto o corpo como um todo, quanto partes localizadas em determinada região do corpo. As oposições ocorrem quando partes do corpo se movem simultaneamente em direções opostas, e semanticamente trazem a negação, a superação ou a dúvida (Stebbins, 1894). Estão relacionadas ao caráter vital e físico do movimento, que se direciona para fora, na intenção gestual de expansão. Delsarte identificou a 
expansividade das oposições como relativas à função antigravitacional do aparelho locomotor, já que forças apontando em direções opostas são necessárias para o homem se manter em pé. As oposições estariam também relacionadas à necessidade humana de se elevar, no sentido de evolução espiritual. Elas desempenhariam um importante papel no peso harmônico, no que tange à maneira como os pontos de apoio do corpo no chão se relacionariam opostamente entre si ao canalizar ou não o peso do corpo, ou seja, um apoio efetiva a descarga de peso enquanto outro se mantém relaxado.

Os paralelismos se dão quando partes do corpo se movem simultaneamente na mesma direção. Segundo Shawn (1963), Delsarte considerava essa ordem de movimento mais limitada expressivamente em relação às outras duas e, do ponto de vista físico, suas formas ofereceriam pouca resistência, estabelecendo bases mais fracas. Roger Garaudy (1980) acrescenta que os paralelismos caracterizam gestos de súplica e de oferenda. Shawn (1963) observa que o paralelismo foi identificado por Delsarte como dominante nas formas das figuras humanas representadas na arte decorativa egípcia e cretense, onde conota movimentos decorativos, estilizados e geometrizados.

As sucessões ocorreriam quando movimentos de diferentes partes do corpo fossem realizados consecutivamente como ondas fluidas, em sucessões de movimentos articulares. Poderiam ocorrer combinadas com torções do tronco, situação em que seriam classificadas como espiraladas. Dentre as três ordens do movimento, as sucessões eram consideradas por Delsarte como a que melhor proporciona a expressão das emoções (Garaudy, 1980). De acordo com Shawn (1963), as sucessões podiam ser de dois tipos: verdadeiras e reversas. As verdadeiras seriam aquelas iniciadas no centro do corpo e direcionadas para as periferias. As reversas começariam em uma extremidade e fluiriam em direção ao centro. As verdadeiras teriam uma denotação moral positiva e, as reversas, uma denotação negativa. Stebbins (1894), de modo diferenciado de Shawn, fala de evolução e involução na ação muscular das sucessões. A evolução seria o conjunto de ações que parte do dentro para o fora: ombro $\rightarrow$ braço $\rightarrow$ cotovelo $\rightarrow$ antebraço $\rightarrow$ pulso $\rightarrow$ mão. A involução começaria no fora para se 
direcionar ao dentro: mão $\rightarrow$ pulso $\rightarrow$ antebraço $\rightarrow$ cotovelo $\rightarrow$ braço $\rightarrow$ ombro.

Para finalizar as explicações derivadas da lei da trindade, é necessário abordar uma importante estrutura delsarteana, o Acorde de Nona ${ }^{12}$; um conjunto de nove elementos resultante da divisão de cada elemento das trindades primordiais em outros três elementos. O acorde de nona é o principal desdobramento da matemática delsarteana, e era tido por Delsarte como molde divino tanto para a criação dos homens, quanto para a dos anjos. No caso dos homens, a trindade vida-almaespírito se desdobraria nos elementos: julgamento, consciência, indução, sentimento, contemplação, intuição, sensação, simpatia e instinto, os quais Delsarte nomeou como Fontes de Atividade do Homem. Também as cores básicas que aparecem nas trindades - o vermelho, o amarelo e o azul - no acorde de nona se desdobram em: verde escuro, violeta, azul, púrpura, vermelho, lilás, amarelo, laranja e verde. Os números se desdobrariam da seguinte maneira: o 1 se transformaria em 1-1, 1-2, 1-3; o 2 em 2-1, 2-2, 2-3; e o 3 em 3-1, 3-2, 3-3. Cada um dos nove elementos do acorde de nona também poderia ser dividido por 9, gerando um quadro complexo de 81 elementos mais detalhados que os de sua matriz. A lógica delsarteana permitiria, teoricamente, que tais divisões ocorressem rumo ao infinito (Shawn, 1963). Na figura baixo se pode visualizar a aplicação do acorde de nona na trindade concêntrico-normalexcêntrico e nas cores elementares:

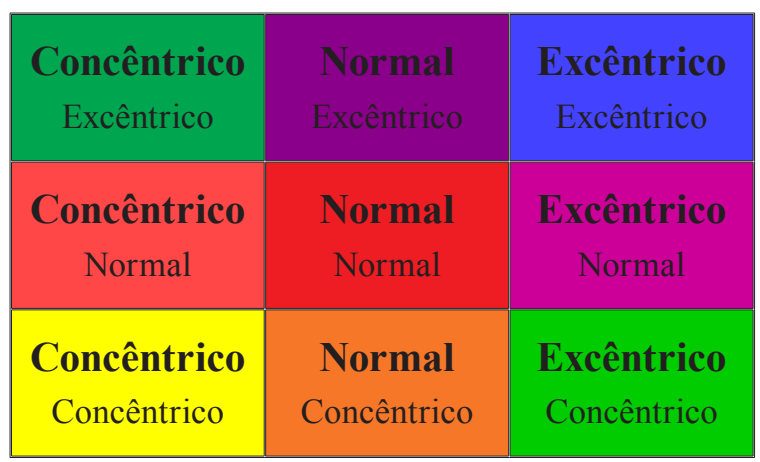

Figura 2 - Quadro do Acorde de Nona dos Critérios da Expressividade Gestual.

Fonte: Autoria própria. Baseado em: Shawn, 1963, p. 30. 
Em relação à interpretação da imagem apresentada acima, Shawn (1963) ressalta que a palavra maior corresponde à tônica dominante, a qual exerce maior influência na expressão, enquanto a menor exerce uma influência subordinada. Os discípulos diretos de Delsarte denominavam a função dominante de gênero e a subordinada de espécie, como o fez Stebbins (1894) e Arnaud (1893). É interessante observar a carga de cientificidade dessas nomenclaturas, e a maneira como refletem a taxonomia de Darwin, que apresenta e relaciona gêneros e espécies de vida.

$\mathrm{O}$ acorde de nona dos critérios do movimento - o desdobramento da trindade concêntrico-normal-excêntrico - é aplicado por Delsarte às partes do corpo humano, criando uma taxonomia da expressividade gestual. Nesse contexto, cada elemento de cada acorde de nona gerado corresponde a uma atitude ou expressão gestual específica e possui um significado básico específico. A significação de cada gesto contemplado em um acorde de nona da expressividade gestual seria reflexo das derivações da trindade vida-alma-espírito. Para concêntrico/excêntrico se teria a significação básica mentalvital; para normal/excêntrico, moral-vital; para excêntrico/ excêntrico, vital-vital; para concêntrico/normal, mental-moral; para normal/normal, moral-moral; para excêntrico/normal, vital-moral; para concêntrico/concêntrico, mental-mental; para normal/concêntrico, moral-mental; e para excêntrico/ concêntrico, vital-mental.

A observação do acorde de nona de uma parte específica do corpo permitiria a identificação de uma escala de entonações expressivas do gestual dessa parte do corpo. Porém, nesse ponto se faz importante observar que Delsarte trabalhou a prática das escalas de partes do corpo como um viés didático, pois considerava que na realidade, assim como na prática cênica, as partes do corpo comumente estariam agindo em conjunto, em combinações que gerariam significados mais complexos, os quais seriam as misturas dos significados básicos (Stebbins, 1894). Abaixo é apresentada uma figura na qual o acorde de nona está sendo aplicado ao corpo como um todo: 


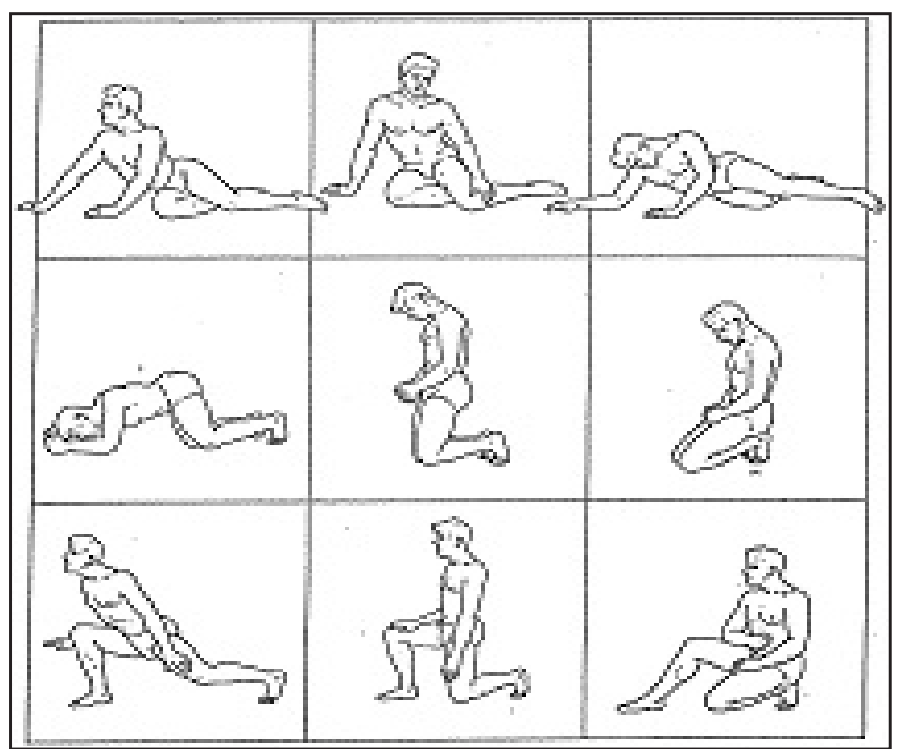

Figura 3 - Acorde de Nona sendo Aplicado ao Gestual de Diversas Partes do Corpo Simultaneamente. Fonte: Giraudet apud Shawn, 1963, p. 113.

\section{A Lei da Correspondência}

A relação que Delsarte traçou entre a estética e a semiótica, a qual se dava como uma via de mão dupla entre forma e significado, foi a base para a elaboração da Lei da Correspondência. Esta lei postula que ação e emoção devem ocorrer de modo consonante na atuação cênica, ou seja, é necessário haver uma coerência entre o gesto feito e o impulso que o causou, ou o que se deseja comunicar. O pressuposto dessa lei é o de que todo gesto nasce de uma emoção, pensamento ou sentimento, e ela implica no fato de que, na via contrária, todo gesto gera uma emoção, pensamento ou sentimento. Para Delsarte, o artista deveria ser essa via de mão dupla. Dizia: "Nada é mais deplorável que um gesto sem motivo, sem significado" (Delsarte, 1984 ${ }^{13}$, s/p apud Shawn, 1963, p. 24 , tradução nossa ${ }^{14}$. Na lei da correspondência entra em jogo uma relação semântica entre forma ou movimento corporal e impulso ou propósito; a gênese das significações gestuais.

No entanto, Delsarte chama a atenção para o fato que considera crucial: a lei da correspondência só irá atuar ${ }^{15}$ na prática do artista cênico quando este estiver sendo verdadeiro, ou seja, quando estiver realizando um gesto verdadeiro. 
Tal adjetivação do gesto remete a uma das três virtudes - a beleza, a verdade e a justiça - buscadas por Delsarte na arte, e diz respeito a uma postura de abertura sensitiva do artista frente à realização de um gesto sabido a priori como portador de tal ou qual significado. O gesto verdadeiro seria aquele atento às sensações que desencadeia; sensível ao chamado da alma. Quando o artista delsarteano estivesse experimentando a contra via da lei da correspondência, a de que gesto implica emoção, ele seria subsidiado pelo esquema semântico gestual elaborado por Delsarte. Esse esquema foi montado a partir das observações feitas por Delsarte quando estudou atentamente as relações entre os gestos vistos e os contextos causadores desses gestos. O esquema de Delsarte deveria guiar o artista, mas não poderia formatá-lo.

Nancy Lee Chalfa Ruyter (1996) atenta para o entendimento de que a relação entre forma e expressão, no contexto da lei da correspondência, é uma relação do estado psicológico com o aspecto funcional do corpo; do que acontece dentro do corpo, com o que extrapola o interior do corpo se reverberando em ações ou movimentos portadores de cargas semânticas. A autora usa os termos tangivel e intangivel no sentido de enfatizar o dentro e o fora. Um exemplo das implicações semânticas concernentes à conexão entre interior e exterior, como expõe Shawn (1963), é a relação que ocorre entre expressão corporal e respiração. A respiração, enquanto fator básico do metabolismo do organismo humano, reflete o equilíbrio homeostático do corpo e, por consequência, o estado nervoso. A capacidade de se comunicar e de refletir, e o rendimento físico são afetados por uma respiração anormal, da mesma maneira que afetam a dinâmica da respiração, levando-a para um estado mais alterado ou mais normalizado. Ainda de acordo com Shawn (1963), Delsarte observou que a respiração tem dois tipos de tempo: um tempo duplo, com um tempo para a inspiração e outro para a expiração; e um tempo triplo, com um tempo para a inspiração, um para a retenção do ar e outro para a expiração. A respiração contida, que considera o tempo da retenção do ar, foi considerada expressivamente importante por Delsarte por indicar suspensão de uma emoção. O pico de uma emoção poderia ser alcançado e comunicado na cena pela 
sintonização do auge de uma gestualidade com a contenção da respiração. Já a sintonização entre a inspiração e o relaxamento de uma tensão corporal poderia indicar o início de uma nova ideia, sensação ou emoção ou, ainda, uma progressão de uma mesma ideia, sensação ou emoção.

\section{As Nove Leis do Movimento}

Também conhecidas como Leis do Gesto, as Nove Leis do Movimento ${ }^{16}$ foram inspiradas na física mecânica. Conforme esclarecido por Ruyter (1996), Delsarte identificou nove fatores do movimento relacionados com a expressão: altitude (altura); força (peso, energia); movimento; sequência; direção; forma; velocidade; reação; extensão. Para cada um desses fatores ele postulou uma lei: Lei da Altura; Lei da Força; Lei do Movimento (contração e expansão); Lei da Sequência; Lei da Direção; Lei da Forma; Lei da Velocidade; Lei da Reação; Lei da Extensão.

De acordo com Stebbins (1894), as três primeiras - a lei da altitude; a lei da força; e a lei do movimento - seriam as leis primárias. A Lei da Altura, ou Lei da Altitude, atesta que quanto mais alto é o gesto, mais positiva é a sequência; quanto mais baixo, mais negativa. Valendo lembrar que a moral delsarteana sempre caminhará na direção da perspectiva católica. Então, positiva se refere ao que é bom, de propósitos mais elevados; e negativa ao que é ruim. Shawn detalha a sentença da lei da altitude: "[...] em geral o construtivo, positivo, bom, verdadeiro, bonito, se move para cima, para frente e para fora - o destrutivo, negativo, feio, falso, se move para trás, para baixo e para dentro" (Shawn, 1963, p. 48, tradução nossa) ${ }^{17}$. Logo, as quedas têm denotação negativa e as elevações, positiva. A Lei da Força postula: uma consciência forte, ou firme (equilibrada) assume atitudes fracas, ou sutis (econômicas; que empregam pouca força e gastam pouca energia); uma consciência fraca (desequilibrada) assume atitudes fortes e exacerbadas (que empregam muita força e gastam muita energia) (Stebbins, 1894). A Lei do Movimento postula que "[...] excitação ou paixão tendem a expandir os gestos; pensamento ou reflexão tendem a contrair os gestos; amor ou 
afeição tendem a produção de um gesto moderado" (Stebbins, 1894 , p. 168 , tradução nossa) ${ }^{18}$. Essa lei segue a mesma lógica que a lei da força, pois, enquanto esta se refere ao impacto da emoção no peso, a lei do movimento se refere a esse impacto na plasticidade do corpo, no sentido de dilatação e retração. Vale ressaltar, ainda de acordo com Stebbins, que pequenas partes do corpo também estariam sujeitas a essa lei, como as narinas e os lábios, os quais eram tidos por Delsarte como os termômetros da paixão na face. As emoções mais desejadas de serem vivenciadas, por serem consideradas divinas, corresponderiam à afeição - o equilíbrio entre paixão e razão. Tais emoções estariam ligadas às mais bonitas modulações e maneiras do corpo.

A Lei da Sequência enuncia que sensação, emoção, sentimento e pensamento antecedem expressão, ação, gesto e palavra. Esse encadeamento indica que a reatividade do indivíduo frente a um acontecido ou a um estímulo interno começa em sua sensitividade, na recepção do mundo, e pode se estender até a ação física ou até a verbalização. Nas palavras de Stebbins: "O gesto é o raio, a fala o trovão; assim, o gesto deve preceder a fala. $O$ gesto mostra a condição emocional da qual fluem as palavras, e as justifica" (Stebbins, 1894, p. 170, tradução nossa) $)^{19}$.

A Lei da Direção tem duas aplicações, uma relacionada às partes do corpo em movimento, e outra ao movimento do corpo no espaço. Seu enunciado é: "O caminho e a direção percorrida pelo gesto indicará sua expressão" (Madureira, 2002, p. 85). De acordo com Shawn (1963), comprimentos se referem à passionalidade, alturas e profundidades ao intelecto e larguras à volição. Para entender os significados dos deslocamentos do corpo na cena, seria necessário perceber suas direções, observando-se seus locais de origem, percurso e término. Para entender a expressão gestual seria necessário observar a origem do movimento no corpo, seu percurso e término. Para se ter esse entendimento, seria necessário o conhecimento das zonas do corpo e do domínio do espaço. As zonas do corpo seriam três e consistiriam em agrupamentos de partes do corpo: zona mental para cabeça e pescoço; zona moral para pelve, abdome e ombros (tronco); e zona vital para 
braços e mãos, e pernas e pés (membros) ${ }^{20}$. Cada uma delas seria portadora de significados, estando intimamente relacionadas com o conceito de domínio do espaço, o qual se refere a uma relação entre parte passiva e parte ativa no movimento do corpo. As partes passivas seriam pontos de partida ou de chegada de gestos dos braços e mãos, e normalmente estariam situadas nas zonas mental e moral. Se fossem ponto de chegada para determinado gesto, acarretariam uma semântica $x$, se fossem ponto de partida, uma $y$ (Shawn, 1963). Stebbins dá o seguinte exemplo: "Nas emoções, se a mão procura o queixo, instintos vitais predominam: os apetites e paixões. Se a mão procura a testa, instintos mentais predominam. Se a mão toca as bochechas, os instintos morais, ou seja, as afeições predominam" (Stebbins, 1894, p. 129, tradução nossa) ${ }^{21}$.

A Lei da Forma relacionaria a dimensão semântica à geometria do gesto. As formas assumidas pelos braços, as linhas da coluna, e mesmo os traços expressivos congênitos das pessoas estariam transmitindo significados de acordo com essa lei. Segundo Shawn,

Formas retas são vitais; formas circulares são mentais; formas espirais são morais, místicas. As formas circulares são, em geral, mais agradáveis, pois o sentimento de prazer é normalmente associado a formas arredondadas, e o sentimento de desconforto a formas angulares (Shawn, 1963, p. 48, tradução nossa) ${ }^{22}$.

A Lei da Velocidade se refere à movimentação pendular, seguindo o postulado da física que diz que a velocidade é proporcional à massa movida e à força movedora. Segundo Ruyter, "[...] a natureza da emoção (a força movedora) e o peso que está sendo movido (o corpo ou suas partes) irão afetar a velocidade do movimento" (Ruyter, 1996, p. 65, tradução nossa). De acordo com Stebbins: "Em proporção à profundidade e majestade da emoção, está a deliberação e vagareza do movimento; e, vice versa, em proporção à superficialidade $\mathrm{e}$ à capacidade explosiva da emoção, está a velocidade de suas expressões em movimento" (Stebbins, 1894, p. 171, tradução nossa) $)^{23}$.

A Lei da Reação deriva da lei da física para ação e reação. Diz que, sob o impacto de uma emoção, o corpo se altera. 
Segundo Stebbins: "Toda emoção extrema tende a causar uma reação de emoção oposta. A retenção de uma paixão tende à explosão; a explosão à prostração. Desse modo, a única emoção que não tende à sua própria destruição, é aquela perfeitamente equilibrada" (1894, p. 172, tradução nossa) ${ }^{24}$.

A Lei da Extensão sentencia que "A extensão do gesto é proporcional ao rendimento da emoção" (Shawn, 1963, p. 49, tradução nossa $)^{25}$. Depois de atingida a extensão máxima do gesto realizado, o corpo tenderia a um relaxamento corporal e o organismo se recuperaria do gasto energético e emocional vivenciado com o esforço que fora empreendido.

\section{O Delsartismo: nascimento de novas expressividades corporais}

Apesar de ter sido um grande investigador da linguagem gestual, Delsarte não se interessou pela dança. Considerava-a uma arte menor, a qual, corporalmente mecanizada, se constituía de artifícios meramente técnicos e de maneirismos da forma. Tal repugnância pode ser mais bem compreendida quando se tem o esclarecimento de que Delsarte se referia ao balé clássico e às danças acrobáticas dos shows de variedades que, em sua época, eram as manifestações cênicas na linguagem da dança que estavam em voga. Identificando uma ausência de expressão genuína nesses gêneros de dança, ele negava essa arte. Considerava intolerável a reprodução tecnicista de procedimentos: "Efeitos performáticos deveriam ser o eco de uma situação claramente compreendida e completamente sentida" (Warman, 1892, s/p apud Shawn, 1963, p. 59, tradução nossa) ${ }^{26}$. Acontece que, mesmo tendo negado a dança, Delsarte foi a grande inspiração da dança moderna, pois suas ideias e leis do movimento possibilitaram aos precursores da dança moderna um instrumental rico para a exploração de novas expressividades corporais. Contudo, como isso se deu?

Essa explicação se inicia com o retorno do americano James Morrison Steele Mackaye (1842-1894) aos EUA, após ter sido aluno de Delsarte (Porte, 1992) em Paris, e de ter se tornado seu discípulo e amigo íntimo. Mackaye começou a dar aulas sobre o sistema de Delsarte e sistematizou um trei- 
no prático para a pantomima delsarteana, o qual chamou de Harmonic Gymnastics, Ginástica Harmônica em português (Ruyter, 1996). Divulgou a Estética Aplicada e a Ginástica Harmônica em diversas cidades dos EUA, teve muitos alunos, formou muitos professores e, juntamente com a ação de outros discípulos de Delsarte, acabou causando o surgimento do Delsartismo, nome que passou a ser usado tanto para aulas práticas como para o movimento social de cultura física que essas práticas desencadearam.

O delsartismo desenvolvido nos EUA, conhecido como delsartismo norte-americano, acabou chegando à Europa, mas nos dois locais o movimento ocorreu de modo diferenciado. $\mathrm{Na}$ Europa, os discípulos foram fiéis aos ensinamentos do mestre, não alterando a estrutura do sistema. Nos EUA, Genevieve Stebbins (1857-1914), que fora aluna de Mackaye, desempenhou um papel de destaque no delsartismo, tendo criado uma escola por onde passaram muitos alunos. Criou inovações na ginástica harmônica de Mackaye, trazendo dinamicidade e abstracionismo para a pantomima delsarteana (Ruyter, 1988). A maior inovação que coube a ela foi a exploração e estilização de movimentos articulares sucessivos em trajetórias espiraladas, podendo ser considerada, de acordo com Ruyter, a verdadeira precursora da dança moderna. Também nos EUA, Henrietta Hovey ${ }^{27}$ teve uma atuação significativa, pois fora professora de delsartismo na Denishawnschool, escola fundada por Ruth St. Denis e Ted Shawn em Los Angeles no ano de 1915 (Shawn, 1963), sendo que o próprio Ted Shawn foi um grande discípulo indireto de Delsarte. Na França e em países próximos, o abade Delaumosne ${ }^{28}$ foi uma figura importante, pois deu aulas para norte-americanos, como Stebbins. Gustave Delsarte e Marie Delsarte-Géraldy, ambos filhos de Delsarte, e seus discípulos, também desempenharam um importante papel.

A forte difusão e influência do delsartismo nos EUA, como ressalta Helen Thomas (1995), se justifica pela compatibilidade entre seu aspecto religioso e o perfil social norteamericano, sendo que ele chegou mesmo a virar uma grande moda, que capturava homens, mulheres, jovens e crianças, e se refletia em produtos que eram vendidos no mercado como xampus, sabonetes e roupas. Nesse contexto, o delsartismo 
foi conteúdo de aulas de educação física em escolas públicas dos EUA, tendo sido também amplamente ensinado em escolas particulares de dança e cultura física. Nesse período, os precursores da dança moderna norte-americana estavam vivendo sua juventude.

\section{Delsarte e a Dança Moderna}

A influência de Delsarte no surgimento da dança se iniciou com o delsartismo, sendo que diversas dançarinas atuantes na passagem do século XIX para o século XX, considerando Isadora Duncan, Ruth Saint Denis e Löie Fuller, tiveram fortes influências de artistas delsartistas (Thomas, 1995). Os números de danças inspirados em culturas consideradas exóticas, os quais eram muito comuns entre os precursores da dança moderna, podem ser levados em conta como uma espécie de continuação da cena desenvolvida pelos delsartistas, como as danças de motivos gregos e espanhóis elaboradas por Genevieve Stebbins. Também a utilização dos elementos da natureza como inspiração para a exploração de dinâmicas de movimento, procedimento comum em Duncan, foi algo experimentado anteriormente por Stebbins (Ruyter, 1988). O estudo que Stebbins empreendeu das esculturas clássicas do Louvre a fim de compreender a manifestação das leis delsarteanas no gestual expressivo humano - que era algo tomado como meta pelos autênticos delsartistas - foi também realizado por Duncan e muitas outras dançarinas contemporâneas a ela. Stebbins costumava dançar descalça e desenvolveu sequências de movimentos que bem poderiam ser considerados passos de dança criados a partir de uma adaptação da prática delsarteana (Ruyter, 1996).

Os argumentos apresentados por Ruyter (1996; 1988), juntamente com muitos dos dados expostos por Thomas (1995), mostram que Saint Denis e Duncan não foram casos isolados, e nem completamente pioneiros, mas, sim, frutos de um meio que produzia muitos perfis artísticos e sociais semelhantes em alguns aspectos. O próprio lema da dança moderna norte-americana em seus primeiros momentos - a dança como uma religião livre - está estreitamente relacionado ao pensamento delsarteano. De acordo com Shawn, a revista 
The Director $^{29}$, na edição de março de 1898 , apresentou uma entrevista em uma matéria intitulada Emotional Expression, na qual Duncan teria dito:

Delsarte, o mestre de todos os princípios de flexibilidade e clareza corporal deveria receber agradecimentos universais pelo cimento que removeu de nossos tensionados músculos. Seus ensinamentos, passados com tanta fé, combinados com a usual instrução necessária para se aprender a dançar, darão um resultado excepcionalmente gracioso e encantador (Duncan, 1898, s/p apud Shawn, 1963, p. 80, tradução nossa ${ }^{30}$.

Quanto a Saint Denis, segundo Ruyter, ela teria ficado profundamente impressionada quando viu, no ano de 1892, aos treze anos de idade, a performance Dance of Day, de Stebbins:

$\mathrm{Na}$ abertura da cena, ela estava deitada no chão adormecida, e então, acordada pelo sol da manhã, se levanta, apoiando-se nos joelhos, em um amável movimento, como uma criança, e se banha nos raios do sol. Dá passos rítmicos e leves que simbolizam a manhã e o meiodia; e então, começa os lentos movimentos da tarde, misturando-os com uma melancolia, enquanto os últimos raios de sol a trazem lentamente de volta ao apoio dos joelhos, e novamente para sua postura reclinada de sono (Ruyter, 1996, p. 72, tradução nossa) ${ }^{31}$.

A influência do sistema de Delsarte na segunda geração da dança moderna norte-americana se deu por intermédio de seus professores e mentores. Martha Graham, Doris Humphrey e Charles Weidman foram alunos da Denishawnschool e lá, por meio de Hovey e Shawn, tiveram contato com o sistema de Delsarte e a prática delsarteana (Garaudy, 1980). Para Shawn (1963), o sistema de Delsarte foi o principal motivador da dança moderna norte-americana, e esteve em todos os núcleos formadores de dançarinos.

Em relação ao desenvolvimento da dança moderna europeia, o delsartismo também desempenhou um papel crucial. No início do século XX, o pensamento e prática delsarteana foi novamente muito divulgado entre o meio artístico europeu, principalmente no ambiente parisiense, sendo que, dessa vez, se difundiram entre artistas e aprendizes da latente dança moderna. Para Bourcier (2001), o delsartismo atingiu a Alemanha 
por meio de Duncan, que o ensinou na escola que fundou em Grünewald. Ruyter (2005), abordando esse tema, desenvolve um ponto de vista mais sociológico, pois, segundo ela, o delsartismo norte-americano chegou por volta do início do século XX à Europa, e em particular à Alemanha, como uma cultura física e estética por meio da ação de inúmeros profissionais e praticantes vindos dos EUA. Para Shawn (1963), a influência delsarteana na dança moderna europeia chegou ao lugar de onde saiu - a Europa - por meio de Duncan e Saint Denis, que foram intensamente admiradas na Alemanha. Por meio delas os conhecimentos delsarteanos teriam sido transmitidos aos precursores da dança moderna europeia, Rudolph Laban e Mary Wigman e, também, aos precursores do balé moderno, dentre eles os russos Vaslav Nijinsky e Michel Fokine. Segundo Shawn, as posturas de paralelismos e a movimentação em perfil utilizadas por Nijinsky no balé l'Après-midi d'un Faune, em português $A$ tarde de um Fauno (obra normalmente associada apenas ao movimento rítmico de Émile Jaques-Dalcroze), foram inspiradas em princípios e observações elaboradas por Delsarte.

Em relação a Laban, é importante observar que ele, assim como Jaques-Dalcroze e Delsarte, tinha um perfil de investigador e fora também influenciado pelo cientificismo da época, que contagiava os estudiosos artísticos e os orientava na elaboração de sistemas teóricos complexos e métodos inovadores. Delsarte foi altamente científico em seus procedimentos investigativos; Jaques-Dalcroze também; Laban também. O senso de observação, assim como em Delsarte e em Dalcroze, também era aguçado em Laban, de modo que suas observações relacionadas ao modo de andar das pessoas, de se portar e de se movimentar durante o trabalho ofereceu a ele uma base sobre a qual pôde começar a desenvolver perguntas e problemas relacionados ao movimento. Laban certamente teve contato com o pensamento de Delsarte, devido à importância comprovada das ideias delsarteanas nas origens da dança moderna, e devido ao fato de ter experimentado diversas linguagens artísticas, como o teatro e a mímica (Newlove; Dalby, 2004).

De acordo com John Hodgson e Valerie Preston-Dunlop (1990), no primeiro momento investigativo de Laban, ele iden- 
tificou o movimento como universal - lugar onde Delsarte e Dalcroze já tinham ido. De acordo com os autores, foi do reconhecimento da universalidade do movimento que Laban evoluiu para o reconhecimento de sua função estrutural. $\mathrm{O}$ estudo desenvolvido por Laban, a respeito do aspecto geométrico do movimento do corpo no espaço, buscava o equilíbrio estético da forma em uma ocupação harmônica do espaço. Essa pesquisa pode ser relacionada com as aplicações das leis estéticas de Delsarte nas formas e movimentos expressivos do corpo. Em relação a conexões que podem ser estabelecidas com as duas principais leis de Delsarte, vale destacar que Laban afirmou que "[...] no corpo humano existe uma unidade triádica: corpo, mente e espírito" (Hodgson; Preston-Dunlop, 1990 , p. 17, tradução nossa) ${ }^{32}$, o que pode ser apontado como um estreito parentesco com a lei da trindade. Para Laban, os três elementos componentes do homem estariam em constante sinergia, realizando um processo de comunicação entre sentimentos, pensamentos e ações:

\footnotetext{
Cada um desses elementos se relaciona no movimento e são interdependentes, e fazem parte de um processo que opera em via dupla: nós sentimos e pensamos, e isso afeta e causa efeitos nos movimentos corporais; movemonos de uma determinada maneira, e isso afeta e causa efeitos em nossa sensação e pensamento. É quase impossível caminhar com a coluna erguida e peito aberto e sentir-se 'para baixo', ou se mover de uma maneira desalinhada e com os ombros caídos, e ter uma sensação saudável, positiva (Hodgson; Preston-Dunlop, 1990, p. 17, tradução nossa) ${ }^{33}$.
}

Observa-se na transcrição acima uma forte proximidade entre as ideias de Laban e a lei da correspondência.

Nas obras de Wigman, a presença de uma movimentação pantomímica abstrata é constante. Em sua coreografia Pastorale $^{34}$, além de desenvolver movimentos espiralados suaves e contínuos de braço, em amplitude pequena, ela trabalha uma poética que se assemelha a motivos de números delsartistas norte-americanos, nos quais a performance gira em torno da ideia do ciclo do dia, com um conjunto de ações corporais que representam o despertar, o erguer-se, o mover-se e o adormecer. Segundo Bourcier (2001), em sua atividade de ensino, 
Wigman trabalhava atenciosamente as articulações da coluna para, a partir daí, levar o aluno a explorar a mobilidade do corpo como um todo. Essa movimentação fora explorada nas aulas de delsartismo norte-americano, quando se direcionava uma atenção detalhada para as articulações entre as vértebras.

Seja na dança moderna norte-americana, seja na europeia, percebe-se que a influência delsarteana foi fortemente significativa. Por meio do background delsarteano, dançarinos e coreógrafos puderam encontrar um leque de possibilidades de exploração do movimento que permitia combinar pesquisa de espaço, de consciência corporal, ou espaço interno, e de significação gestual. Esses três fatores podem ser de fato identificados na dança moderna como diretrizes da exploração da expressividade do movimento. A partir de investigações relacionadas aos desdobramentos concernentes a cada uma dessas três abordagens, os precursores e desbravadores da dança moderna, em meio a um ambiente complexo de influências e descobertas, desenvolveram estéticas e poéticas pessoais que acabaram se tornando estilos de dança.

\section{Considerações Finais}

O espírito de renovação artística e de libertação psíquica e corporal que estava fundamentalmente presente no Delsartismo norte-americano certamente atuou nos agenciamentos de ideias artísticas e sociais que deram chão às atitudes estéticas e poéticas inovadoras na dança moderna. O sistema de Delsarte foi compreendido e utilizado de diversas maneiras pelos profissionais delsartistas, e, independentemente destes terem massivamente ou parcialmente distorcido a maneira de se aplicar os princípios e leis delsarteanas ao movimento, eles ensinaram amplamente posturas e inflexões delsarteanas e divulgaram práticas corporais performáticas baseadas nelas. O pensamento de Delsarte foi por eles tanto engolido, como ruminado; inspirou os sonhos artísticos de jovens e adultos e fez desabrochar diversos festivais e publicações. Acabou se tornando nutrição para a atitude em prol da renovação e da libertação expressiva enfrentada pelos precursores da dança moderna. 


\section{Notas}

${ }^{1}$ Delsarte abordava o conceito de gesto como expressão inconsciente ou consciente de sensações, sentimentos e pensamentos, podendo o gesto ser vocal ou corporal.

${ }^{2}[. .$.$] how far particular gestures are really expressive of certain states of the mind [...]$

${ }^{3}[. .$.$] how the human body moves under the stimuli of emotions [...]$

${ }^{4}$ Delsarte não chegou a lapidar sua teoria para um formato de publicação, de modo que as fontes nas quais se pode buscar um entendimento a respeito da Estética Aplicada são os livros dos discípulos de Delsarte, além dos manuscritos elaborados por ele próprio. No livro François Delsarte: une anthologie, referenciado neste artigo, Allan Porte juntou e comentou os manuscritos de Delsarte, os quais correspondem a conferências preparadas para palestras, rascunhos, anotações, cartas, quadros esquemáticos e desenhos.

${ }^{5}$ Shawn explica na página 22 que os trechos escritos por Delsarte citados nas páginas seguintes foram retirados do livro de Stebbins (1894), especificamente do suplemento que consiste na palestra que Delsarte fez na Sociedade Filotécnica de Paris, publicada na obra.

${ }^{6}$ The most powerful of all gestures is that which affects the spectator without his knowing it.

${ }^{7}$ A partir desse ponto do texto, o termo 'gesto' se referirá à 'gesto corporal'.

${ }^{8}[. .$.$] the science of the sensitive and passional manifestations which are the object of art, and$ whose psychic form it constitutes.

${ }^{9}[\ldots .$.$] the science of the organic signs by which aesthetics must study inherent fitness.$

${ }^{10}[. .$.$] the form assumed by the human being at birth, or constitutional form; the form which under$ the influence of environment and customs and growing experience undergoes modifications, which is habitual form; and the form taken under the sway of temporary emotion, which is fugitive form.

${ }^{11}$ Passional types explain habitual types, and habitual types explain congenital types.

${ }^{12}$ Do original em francês: Accord de Neuvième.

${ }^{13}$ Equivalente à nota 5 (acima).

${ }^{14}$ Nothing is more deplorable than a gesture without a motive, without meaning.

${ }^{15}$ Lembrando que Delsarte trabalha suas leis na perspectiva estreita do termo, ou seja, enquanto determinações naturais do funcionamento das coisas no mundo. Ocorrendo que em sua perspectiva religiosa, esse sentido rígido do termo lei se flexibiliza, pois estas equivalem a determinações de Deus.

${ }^{16}$ Angelique Arnaud, discípula de Delsarte, informa que Delsarte elaborou seis leis para o movimento. Porém, seus discípulos Delaumosne e Genevieve Stebbins afirmam que foram nove.

${ }^{17}$ [...] in general, the constructive, positive, good, true, beautiful, moves upward, forward and outward - the destructive, negative, ugly, false, moves downward, inward and backward.

${ }^{18}$ Excitement or passion tends to expand gesture; Thought or reflection tends to contract gestures; Love or affection tends to moderate gestures. 
${ }^{19}$ Gesture is the lightning, speech the thunder; thus gesture should precede speech. The gesture shows the emotional condition from which the words flow, and justifies them.

${ }^{20}$ Encontra-se na literatura da área diferenças nessas divisões.

${ }^{21}$ In emotion, if the hand seeks the chin, vital instincts predominate: namely, apetites, passions; While if the hand seeks the forehead, the mental instincts predominate; If the hand touches the cheeks, the moral instincts; that is, the affections predominate.

${ }^{22}$ Straight form is vital; Circular form is mental; Spiral form is moral, mystic. Circular form is, generally speaking, more pleasing, due to its associations with the pleasant feel of round things as against angular objects; and thus by implication, angular forms are more unpleasant.

${ }^{23}$ In proportion to the depth and majesty of the emotion, is the deliberation and slowness of the motion; and, vice versa, in proportion to the superficiality and explosiveness of the emotion, will be the velocity of its expression in motion.

${ }^{24}$ Every extreme of emotion tends to react to its opposite. Concentrated passion tends to explosion; explosion to prostration. Thus the only emotion which does not tend to its own destruction, is that which is perfectly poised.

${ }^{25}$ The extension of the gesture is in proportion to the surrender of the will in emotion.

${ }^{26}$ Effects should be the echoes of a situation clearly comprehended and completely felt.

${ }^{27} \mathrm{O}$ sobrenome de nascença de Henrietta Hovey era Knapp. Devido a seus três casamentos, teve outros dois sobrenomes além de Hovey: Crane e Russel (Ruyter, 2005, p. 15).

${ }^{28}$ Delaumosne escreveu Pratique de l'art oratoire de Delsarte (1874), a primeira publicação dedicada à estética aplicada.

${ }^{29}$ Segundo Shawn (1963, p.79), a mais antiga publicação periódica de dança publicada nos EUA.

${ }^{30}$ Delsarte, the master of all principles of flexibility, and lightness of body, should receive universal thanks for the bonds he has removed from our constrained members. His teachings, faithfully given, combined with the usual instruction necessary to learning to dance, will give a result exceptionally graceful and charming.

${ }^{31}$ At the opening of the scene, she was lying on the floor asleep, and then, awakened by the morning sun, she rose with a lovely childlike movement to her knee and bathed herself in its rays. A light rhythmic step signified the morning and the noontide; and then began the slower movements of the afternoon, presently mingled with sadness as the late rays brought her slowly to her knees and again into her reclining posture of sleep.

32 [...] in the human body there is a three-fold unity: body, mind and spirit.

${ }^{33}$ Each of these is movement-related and interdependente and throughout there is a two-way process in operation: we feel, we think and that affects and effects body movement; we move in a certain way and that affects and effects outlook and thought. It is well-nigh impossible to walk tall and open and feel 'down', or to move in a slovenly, round-shouldered fashion and have a healthy, positive outlook.

${ }^{34}$ Essa coreografia pode ser conferida no endereço: <www.europafilmtreasures.eu>. 


\section{Referências}

ARNAUD, Angélique. The Delsarte System. Delsarte System of Oratory. New York: Edgar, S. Werner, 1893. p. 171-379. Disponível em: <http://archive.org/details/delsartesystemof00delauoft>. Acesso em: 21 jul. 2012.

BOURCIER, Paul. História da Dança no Ocidente. São Paulo: Martins Fontes, 2001.

CARDIM, Leandro Neves. Corpo. São Paulo: Globo, 2009.

DASGUPTA, Gautam. Commedia Delsarte. Performing Arts Journal, Cambridge, v. 15, n. 3, p. 95-102, set. 1993.

DELAUMOSNE. Delsarte System of Oratory. New York: Edgar, S. Werner, 1893. p. XVIIXXIX; 3-165. Disponível em: $<$ http://archive.org/details/delsartesystemof00delauoft $>$. Acesso em: 21 jul. 2012.

DELSARTE, François. Address of François Delsarte before the Philotechnic Society of Paris. In: STEBBINS, Genevieve. Delsarte System of Expression. New York: Edgar S. Werner, 1894. P. XI-LVIII.

FAHEY, Joseph. Quiet Victory: the professional identity American women forged through Delsartism. Mime Journal, Claremont, 2004/2005, p. 42-83, 2005. Essays on François Delsarte.

GARAUDY, Roger. Dançar a Vida. Rio de Janeiro: Editora Nova Fronteira, 1980.

HECHT, Patsy Ann Clark. Kinetic Techniques for the Actor: an analysis and comparison of the movement training systems of François Delsarte, Emile Jaques-Dalcroze and Rudolf Laban. 1971. Tese (Doutorado em Filosofia) - Divisão de Pós-Graduação, Wayne State University, Detroit, 1971.

HODGSON, John; PRESTON-DUNLOP, Valerie. Rudolf Laban: an introduction to his work \& influence. Plymouth: Northcote House, 1990.

MADUREIRA, José Rafael. François Delsarte: personagem de uma dança (re)descoberta. 2002. Dissertação (Mestrado em Educação) - Programa de Pós-Graduação em Educação, Universidade Estadual de Campinas, Campinas, 2002.

MENERTH Jr., Edward F. Two Mirrors of Movement. Art Journal, New York, v. 28, n. 1, p. 50-53, outono 1968.

NEWLOVE, Jean; DALBY, John. Laban for All. London: Nick Hern Books; New York: Routledge, 2004.

PORTE, Alain. François Delsarte: une anthologie. Paris: Edition IPMC, 1992.

RUYTER, Nancy Lee Chalfa. The Cultivation of Body and Mind in Nineteenth-century American Delsartism. London: Greenwood Press, 1999.

RUYTER, Nancy Lee Chalfa. The Delsarte Heritage. Dance Research: The Journal of the Society for Dance Research, Edimburgo, v. 14, n. 1, p. 62-74, verão 1996. 
RUYTER, Nancy Lee Chalfa. The Intellectual World of Genevieve Stebbins. Dance Chronicle, New York, v. 11, n. 3, p. 381-397, 1988.

RUYTER, Nancy Lee Chalfa. Prefácio. In: SHAWN, Ted. Chaque Petit Mouvement: à propos de François Delsarte. Paris: Éditions Complexe; Centre National de la Danse, 2005. P. 7-20.

SHAWN, Ted. Every Little Movement: a book about Delsarte. New York: Dance Horizons, 1963.

STEBBINS, Genevieve. Delsarte System of Expression. New York: Edgar S. Werner, 1894.

TAYLOR, George; WHYMAN, Rose. François Delsarte, Prince Sergei Volkonsky and Mikhail Chekhov. Mime Journal, Claremont, 2004/2005, p. 96-111, 2005. Essays on François Delsarte.

THOMAS, Helen. Dance, Modernity \& Culture: explorations in the sociology of dance. New York: Routledge, 1995.

Elisa Teixeira de Souza é dançarina e graduada em dança pela Universidade Federal da Bahia, mestre em Artes pela Universidade de Brasília e doutoranda no Programa de Pós-Graduação em Artes da Universidade de Brasília.

E-mail: elisatex@gmail.com

Recebido em 30 de junho de 2012 Aprovado em 06 de setembro de 2012 